\title{
Perfil das redes de cooperação científica: congresso USP de controladoria e contabilidade - 2001 a $2009^{*}$
}

\section{Profile of scientific cooperation networks at congresso USP de controladoria e contabilidade in 2001-2009}

\author{
Ana Paula Capuano da Cruz \\ Doutoranda em Controladoria e Contabilidade do Departamento de Contabilidade e Atuária da Faculdade de Economia, Administração e \\ Contabilidade da Universidade de São Paulo \\ E-mail: anapaulacapuanocruz@hotmail.com
}

\begin{abstract}
Márcia Maria dos Santos Bortolocci Espejo
Professora Adjunta do PPG Mestrado em Contabilidade do Departamento de Contabilidade do Setor de Ciências Sociais Aplicadas da Universidade Federal do Paraná

E-mail: marciabortolocci@ufpr.br
\end{abstract}

Flaviano Costa

Professor Mestre da Faculdade de Ciências Sociais Aplicadas do Paraná (FACET)

E-mail; flaviano_costa@hotmail.com

Lauro Brito de Almeida

Professor Adjunto do PPG Mestrado em Contabilidade, Setor de Ciências Sociais Aplicadas da Universidade Federal do Paraná

E-mail: gbrito@uol.com.br

Recebido em 20.07.2010 - Aceito em 15.09.2010 - $3^{a}$ versão aceita em 04.03.2011

\section{RESUMO}

Este estudo objetivou delinear o perfil das redes de cooperação configuradas entre os pesquisadores envolvidos no Congresso USP de Controladoria e Contabilidade, mapeando, a partir da estrutura de relacionamento, a forma de cooperação manifestada no período 2001-2009. Trata-se de um artigo descritivo, de natureza quantitativa que, a partir de conceitos de redes sociais de colaboração, mapeou a estrutura de relações configurada entre os 1.120 autores envolvidos nos 882 artigos científicos veiculados em 9 edições do Congresso. Os dados foram coletados dos anais do evento e tratados trienalmente com auxílio do software Ucinet 6.0. Os achados evidenciaram que parte dos atores ocupou posição privilegiada na estrutura da rede, mostrando-se abertos a outros grupos e assumindo posições de pontes que ligaram pesquisadores que não estariam conectados sem a sua presença. Em linhas gerais, o perfil das redes de cooperação mostrou-se predominantemente caracterizado pela presença de laços fortes. Embora se tenha identificado um perfil de redes de cooperação deficiente em alguns quesitos, o universo explorado apresentou sinais de desenvolvimento. A rede teve sua densidade aumentada no último período e houve diminuição das relações fortes. Porém, poucos autores responderam por parcela significativa da produção científica, além de baixa persistência de pesquisadores ao longo do período analisado. As maiores sub-redes de cada um dos triênios analisados reuniram os atores relevantes em termos de número de artigos selecionados e centralidades de grau e de intermediação. Diante de um grande número de pesquisadores que têm metas comuns e vislumbra a internacionalização como necessidade premente, o estudo instiga reflexões sobre a coordenação de esforços que se poderia instaurar no sentido de promover a colaboração científica, em seu sentido amplo, como forma de cooperar para a manutenção e evolução de um empreendimento tão 
relevante na comunidade acadêmica: a pesquisa em Contabilidade.

Palavras-chave: Redes de cooperação. Congresso USP de Controladoria e Contabilidade. Pesquisa em Contabilidade.

\section{ABSTRACT}

The study aimed to define the profile of cooperation networks set up between researchers involved in Congresso USP de Controladoria e Contabilidade, mapping based on the structure of relationships, the cooperation form manifested in the period 2001-2009. Starting from the social nets of collaboration concepts, this descripitive and quantitative study mapped the structure of relationships establishead among the 1120 authors involved in 882 scientific papers transmitted in nine editions of the Congress. The data were collected from the annals of the event and analyzed each three years with the aid of Ucinet 6.0 software. The findings indicated that part of the actors occupied a privileged position in the network structure, being receptive to other groups and assuming positions of bridges that connected researchers who would not be connected without their presence. In general, the profile of cooperation networks proved to be predominantly characterized by strong ties. While a deficient profile of cooperation networks was identified in some cases, the research universe showed signs of development. The network had its density increased in the last period and there was a decrease in string relations. Few authors were responsible for a significant portion of scientific production though, besides low persistence along the analyzed period. The largest sub-networks of each of the analyzed three-year periods gathered the most relevant actors in terms of number of selected papers and degree of centralities and intermediation. In view of a large number of researchers who have common goals and see internationalization as an urgent need, the study encourages reflection on the coordination of efforts that could be introduced in order to promote scientific collaboration in its broadest sense as a way to cooperate towards the maintenance and evolution of an enterprise so important in the academic community-Accounting research.

Keywords: Cooperation networks. Congresso USP de Controladoria e Contabilidade. Accounting Research.

\section{INTRODUÇÃO}

A formação de parcerias para o desenvolvimento de pesquisas é prática frequente no meio científico. A colaboração entre pesquisadores possibilita o compartilhamento de uma variedade de recursos informacionais, tecnológicos, além de experiências, ideias, entre outras trocas. Assim, o esforço conjunto desses sujeitos no processo de desenvolvimento de investigações pode ser compreendido como uma das formas de produção de conhecimento científico (KATZ; MARTIN, 1997).

Confirmando a importância da formação de redes de cooperação, uma das funcionalidades da versão mais recente do currículo Lattes lançada pelo Conselho Nacional de Desenvolvimento Científico e Tecnológico
(CNPq) permite a visualização gráfica da rede de coautores de pesquisas que trabalham de forma conjunta. Desenvolvida com base em informações que registram a vida pregressa e atual de pesquisadores, a iniciativa de ilustrar a rede de cooperação, a partir de dados constantes da Plataforma Lattes, reforça a utilidade de reflexões acerca da estrutura de relacionamento que dá origem à produção científica.

Com relação à consolidação da área de Contabilidade no Brasil, observa-se que a maior parte de seus Programas de Pós-Graduação foi criada na última década (CAPES, 2010). Complementarmente, ressalte-se que a produção científica em Contabilidade parece estar em processo de amadurecimento, haja 
vista a ampliação da oferta de espaços específicos para essa área no último encontro promovido pela Associação Nacional dos Programas de Pós-Graduação em Administração (ANPAD), bem como a realização de dois congressos expressivos (em termos de classificação no Qualis/CAPES) desse campo de pesquisa: Congresso USP de Controladoria e Contabilidade e Congresso da Associação Nacional dos Programas de Pós-Graduação em Ciências Contábeis (ANPCONT).

A análise de redes sociais (ARS) tem sido objeto de interesse de várias áreas do conhecimento. Entre os estudos realizados, destacam-se: (I) Rossoni (2006) no campo de Organizações e Estratégia; (II) Graeml et al. (2010) no campo da Administração da Informação; (III) Bittencourt e Kliemann Neto (2009) no campo de Sistemas de Saúde; (IV) Mello, Crubellate e Rossoni (2010) no campo de Programas de Pós-Graduação em Administração, bem como (V) Nascimento e Beuren (2011) no campo de Programas de PósGraduação em Ciências Contábeis.

Apesar do interesse manifestado em diversas áreas, Fleischman e Schuele (2009) afirmam que pouco tem sido escrito sobre coautoria em Contabilidade. Portanto, considerando o amplo interesse das áreas e que artigos científicos, tanto àqueles individualmente realizados, quanto àqueles produzidos a partir da perspectiva colaborativa, representam um meio de conversação entre atores sociais, este estudo é orientado pela seguinte questão de pesquisa: Qual o perfil das redes de cooperação configuradas entre os pesquisadores envolvidos no Congresso USP de Controla- doria e Contabilidade no período 2001-2009? Desse modo, objetiva-se delinear o perfil das redes de cooperação configuradas entre os pesquisadores envolvidos no Congresso USP de Controladoria e Contabilidade, mapeando, a partir da estrutura de relacionamento, a forma de cooperação manifestada entre os atores com artigos aceitos no referido evento, no período 2001-2009.

A contribuição esperada é que, ao revelar o atual estágio do formato de configuração relacional da pesquisa em Contabilidade, os achados da pesquisa subsidiem discussões que possibilitem uma melhor compreensão por parte de pesquisadores e Programas de Pós-Graduação como um todo, da importância de se refletir acerca do processo de estruturação da produção científica. Diante de um campo de pesquisa relativamente jovem, como é o caso da Contabilidade, tal reflexão mostra-se salutar à comunidade acadêmica da área. Visualizada como um empreendimento que envolve metas comuns, esforços coordenados e produtos (trabalhos científicos) com responsabilidade e mérito compartilhados, a colaboração científica manifestase como uma postura positiva e que deve ser valorizada.

$\mathrm{O}$ artigo está estruturado em mais quatro seções. A seguir, na segunda seção, tem-se o quadro teórico de referência relativo às redes sociais de colaboração. Na sequência, a terceira seção expõe os procedimentos metodológicos. A seção quatro destina-se à exposição da análise dos dados e discussão dos resultados e, por fim, a quinta seção reúne os argumentos conclusivos do estudo.

\section{REDES SOCIAIS DE COLABORAÇÃO}

Wasserman e Faust (1994) conceituam redes sociais como um ou mais conjuntos finitos de atores e as relações estabelecidas entre eles. Martins (2009) acrescenta que as redes sociais representam conjuntos de contatos (de diferentes tipos, conteúdos e proprie- dades estruturais) que ligam vários atores. Cumpre observar que, conforme asseveram Emirbayer e Goodwin (1994), a análise de redes sociais não constitui uma teoria formal e sem relacionamentos com o ambiente, mas uma estratégia significativa relacionada ao 
estudo das estruturas sociais, de caráter eminentemente interdisciplinar.

\subsection{Conceitos fundamentais}

Na visão de Hanneman e Riddle (2005), os estudos de redes sociais desenham limites em torno de uma população, de modo que a rede estudada pode representar uma agregação imposta pelo pesquisador. Segundo Wasserman e Faust (1994), as análises de redes sociais (Social Network Analysis) têm atraído interesse e curiosidade consideráveis da comunidade de pesquisadores das áreas social e comportamental nas últimas décadas; interessam-se pelas ligações entre entidades sociais, as quais são denominadas atores. Ainda, esclarecem que o uso do termo "ator" não implica, necessariamente, que tais entidades sociais tenham vontade ou capacidade de agir.

As ligações entre os atores constituintes de uma rede são materializadas por meio de laços relacionais (WASSERMAN; FAUST, 1994), ilustrativamente representados pelos caminhos que ligam dois ou mais atores. Subjacente à noção de laço, destaca-se o conceito de lacunas estruturais (structural hole) que, segundo Machado-da-Silva e Coser (2008), pode esclarecer aspectos relacionados com tentativa de mudança em uma rede social. Desenvolvido por Burt, em 1992, o referido conceito explora implicações decorrentes de conexões com diferentes características, mesmo que constituintes de uma mesma rede de cooperação.

As lacunas estruturais representam brechas no fluxo de informações, indicativas das relações não repetidas entre atores e que têm a faculdade de fornecer o que Burt (2004) denomina de capital social de intermediação. A manifestação de lacunas estruturais é inversamente proporcional ao número de laços redundantes; assim, quanto mais laços desse tipo houver em uma rede, maior a redundância da informação compartilhada e, consequentemente, menor o número de lacunas estruturais presentes. $\mathrm{O}$ ator que assume o papel de intermediador tem posição privilegiada na rede, pois tem acesso antecipado às informações, podendo visualizá-las mais amplamente e, ainda, agenciar o seu repasse aos demais integrantes do grupo. Nesse sentido, relacionamentos caracterizados pela presença de intermediadores provêm capital social; um recurso que deriva da estrutura coletiva, porém é transmitido aos indivíduos em doses distintas, logo, não facilita, igualmente, todos os atores (BURT, 2004; OWEN-SMITH; POWELL, 2008). Para Burt (2004), a existência de capital social está condicionada ao posicionamento de um ator na estrutura social que, por sua vez, é decorrente de vantagem representada pelo lugar que ocupa.

Em manifestação anterior à Burt (2004), Granovetter (1973, 1983) desenvolveu uma argumentação que atenta para a força dos laços fracos na análise de redes, defendendo que os indivíduos que apresentam poucos laços fracos são privados de informações provenientes de partes distantes do seu sistema social e limitados às notícias do seu círculo de convívio e inclusive, à visão de seus contatos diretos. Assim, os laços fracos representam conexões indiretas entre pesquisadores, intermediadas por alguns atores. Isoladamente, tais laços não têm grande importância, mas, algumas vezes, podem assumir a função de pontes, as quais se configuram na ocasião em que só um elemento da rede está conectado a outra rede, sendo de grande valia, uma vez que permitem a ligação entre diferentes mundos, podendo auxiliar na mudança e na inovação. Assim, as lacunas estruturais são indicadores de laços fracos.

Os laços fortes caracterizam-se pelas ligações diretas entre autores, expressando, teoricamente, uma relação de maior comprometimento e responsabilidade. Na sequência, a próxima subseção destina-se à exposição de uma dimensão passível de exploração em redes sociais: propriedades estruturais e abordagem relacional. Porém, conforme Wasserman 
e Faust (1994), existem métodos alternativos para a condução de análises de redes sociais (propriedades estruturais; papéis e posições; e análises estatísticas das relações).

\subsection{Propriedades estruturais e abordagem relacional}

Apoiada nas propriedades estruturais de uma rede, a abordagem relacional configurase como um recurso para compreender comportamentos e processos a partir da conectividade entre os atores interligados em uma rede. Sob a égide dessa abordagem, uma série de medidas é explorada na literatura: centralidade, equilíbrio e transitividade, coesão de grupos (WASSERMAN; FAUST, 1994). Em virtude da disponibilidade de dados, para o desenvolvimento deste estudo, optou-se pela análise de propriedades estruturais a partir de medidas de centralidade e densidade.

A centralidade é uma das propriedades de redes utilizada com bastante frequência; sua noção geral envolve aspectos relacionados à importância ou visibilidade de um ator em uma rede (MEMON et al., 2008). Degenne e Forsé (1999) argumentam que a centralidade é um atributo estrutural essencial, porém, de difícil quantificação, haja vista que não há consenso acerca de sua definição. Como a ideia de centralidade pode assumir diferentes significados, há, também, modos distintos de mensurá-la. Dentre os tipos de centralidades discutidos por Linton Freeman (DEGENNE; FORSÉ, 1999), destacam-se para a realização deste estudo: [I] centralidade de grau (degree) e [II] centralidade de intermediação (betweenness). A centralidade de grau é obtida a partir do número de links diretos que um ator possuiu e a medida de centralidade de intermediação considera se um ator assume, ou não, posição de intermediador (DEGENNE; FORSÉ, 1999). Complementarmente, para Scott (2000), um ator é localmente central se possui um grande número de laços conectivos com outros pontos e, globalmente central, se apresentar posição estratégica significativa na rede.
Também, relevante para análise de redes sociais é o conceito de densidade: uma tentativa de resumir toda a distribuição de links para medir a distância entre as posições ocupadas, indicativa do nível geral de articulação entre os atores integrantes de uma rede (SCOTT, 2000). Segundo o autor, a densidade representa uma relação entre o número de laços manifestados e possíveis no grupo. Assim, valores próximos de 1 indicam uma rede altamente conectada e valores que se aproximam de 0 caracterizam uma rede com poucas conexões. Adicionalmente, Emirbayer e Goodwin (1994) definem densidade como a proporcionalidade das relações ou laços existentes entre um conjunto de atores em uma rede, determinando, assim, o número possível de laços. Por fim, saliente-se que componente representa uma espécie de subrede totalmente conectada entre si, ou seja, um conjunto de atores ligados uns aos outros, formativos de uma cadeia de conexão contínua (SCOTT, 2000).

\subsection{Integrando análise de redes sociais e produção científica}

Sabe-se que, em um campo de pesquisa, a colaboração manifesta-se, entre outras formas, por meio de publicações conjuntas. Para Katz e Martin (1997), colaboração científica pode ser definida como o trabalho conjunto de pesquisadores que têm como objetivo comum a produção de novo conhecimento. $\mathrm{Na}$ visão dos autores, são colaboradores de um estudo aqueles indivíduos que: (I) trabalharam em grande parte (ou toda) da investigação ou fizeram contribuições frequentes ou substanciais; (II) foram nominados na proposta inicial de estudo; (III) responsabilizaram-se pelos principais elementos da pesquisa (projeto experimental, construção de equipamentos, execução de experimento, análise e interpretação de dados, redação dos resultados etc.) e/ou (IV) trabalharam em etapas- chave (ideia original, hipótese, interpretação teórica etc.). 
Conceição (2008) manifesta preocupação similar à de Katz e Martins (1997) com relação à ideia de colaboração que supostamente esteja institucionalizada no ambiente acadêmico. Ao discutir a possibilidade de inclusão de autores em artigos científicos que não tenham participado, efetivamente, de sua elaboração, Conceição (2008) questiona o sentido de colaboração que estaria subentendido a partir dos autores e coautores mencionados em uma pesquisa. Nesse aspecto, a autora salienta que os editores de periódicos científicos têm sido encorajados a adotar postura que contribua para minimizar a adição de coautores por estrita conveniência de uma das partes. Adiciona, ainda, que "algumas revistas, em especial das áreas da saúde [...] vêm adotando o procedimento de solicitar a explicitação da contribuição de cada um dos autores na confecção do manuscrito, quando de sua submissão ao comitê editorial" (CONCEIÇÃO, 2008, p. 1), evidenciando assim, preocupação quanto à atribuição de crédito a coautores que, efetivamente, tenham contribuído para o desenvolvimento da pesquisa.

Apesar de questionarem o significado de colaboração em pesquisas científicas, Katz e Martin (1997) reconhecem que a exploração da perspectiva colaborativa por meio de redes de coautorias configura-se como um recurso exequível, de metodologia relativamente prática e de baixo custo, que possibilita contemplar amostras significativas para a mensuração da colaboração. Logo, os autores salientam que há validade na exploração de colaboração a partir de redes de coautorias; todavia, advertem que esse tipo de mensuração implica obtenção de um indicador parcial da atividade colaborativa.

As redes de coautoria representam uma importante classe de redes sociais e têm sido, ampla e crescentemente, utilizadas para determinar estruturas de colaboração científica e status de pesquisadores que trabalham de forma isolada (LIU et al., 2005). Conforme Silva et al., (2005), a análise de redes sociais
(ARS) pode ser aplicada como instrumento avaliativo da produção científica, permitindo a observação de aspectos decorrentes da colaboração manifestada entre pesquisadores e materializando-se como ferramental adicional para estudos bibliométricos (SILVA et al., 2006). A ARS pode ser conjugada com pesquisas sobre produção científica, explorando-se redes de citação, cocitação, coautorias, estruturas de colaboração e outras formas de redes de interação social (OTTE; ROUSSEAU, 2002). Conforme Barabási et al. (2002, p. 2), redes de coautorias manifestam links profissionais entre pesquisadores e, para sua operacionalização, considera-se que "dois cientistas estão ligados se escreverem um artigo juntos".

Dentre os estudos que têm explorado as redes de coautorias, destaca-se a pesquisa de Acedo et al. (2006), que, a partir de 14.597 documentos (artigos, notas de pesquisa, editoriais, etc.) publicados em dez dos principais journals americanos e europeus, exploraram: (I) fatores determinantes da coautoria; (II) se a colaboração afeta o impacto de um estudo publicado e (III) a estrutura social manifestada na colaboração científica formalizada em estudos organizacionais publicados entre $1980 \mathrm{e}$ 2002. No que diz respeito à estrutura de relacionamento configurada entre os pesquisadores, constataram que, dentre os 10.176 autores identificados, mais de 65\% participaram de um único artigo, além da presença de inúmeros componentes desconectados do resto da rede. A maior sub-rede reuniu pouco mais de $45 \%$ dos autores e o número de componentes grandes foi baixo, tendo sido constatados 761 componentes de dois autores, 280 de três, 138 de quatro, 67 de cinco, 26 de seis e 23 de sete. Segundo os autores, as características da rede não se mostraram muito diferentes daquelas manifestadas em outras disciplinas como ciência da computação e sociologia, porém exibiram traços bastante distintos, especialmente densidade e tamanho do componente central, das ciências naturais. Os autores centrais e pro- 
eminentes (em termos de número de artigos e laços) estiveram, em sua maioria, conectados uns com os outros.

Dentre os estudos internacionais voltados para a perspectiva de redes e Contabilidade, destacam-se as pesquisas de Wakefield (2008), Englebrecht, Hanke e Kuang (2008), Rutledge e Karim (2009) e Ulysal (2010). Wakefield (2008) explorou redes de pesquisa contábil a partir da mensuração da influência, em termos de quantidade e qualidade de citações, de 22 periódicos de Contabilidade no período 2000-2006. Apoiando-se na análise de citações, o autor constatou que, apesar de serem muito citadas, algumas revistas podem ser menos influentes na comunidade de pesquisa contábil. Os achados sugerem que os periódicos mais influentes podem assumir diferentes papéis no campo de pesquisa contábil.

Englebrecht, Hanke e Kuang (2008) analisaram aspectos de coautoria manifestados por pesquisadores contábeis a partir de premier journals, no período 1979-2004. Constataram que a colaboração está crescendo significati- vamente e que a prática de coautoria se mostra menos comum dentre taxation researchs, manifestando-se, de forma mais expressiva, em investigações de naturezas financeira, gerencial e de auditoria. Os autores sugerem que estudos futuros investiguem como as redes de coautorias têm evoluído ao longo do tempo.

Rutledge e Karim (2009) analisaram as características dos artigos publicados pelos autores mais produtivos da literatura contábil, dispensando especial atenção ao nível de colaboração manifestado. Os achados sinalizam que os autores mais prolíficos tornam-se mais produtivos e produzem pesquisas mais amplas trabalhando de forma conjunta. Por fim, Ulysal (2010) pesquisou um amplo conjunto de periódicos sobre ética nos negócios, com ênfase na Contabilidade, no período de 1988-2007. Tal pesquisa foi operacionalizada por meio de técnicas bibliométricas, análise de citações e ferramentas para análise de redes sociais para a determinação das características de centralidade das redes de cocitação dos documentos analisados.

\section{PLATAFORMA METODOLÓGICA}

Para delinear o perfil das redes de cooperação configuradas entre os pesquisadores envolvidos no Congresso USP de Controladoria e Contabilidade, desenvolveu-se um estudo descritivo, de natureza quantitativa, cuja análise documental é realizada com emprego de técnicas bibliométricas e de redes sociais de cooperação. Estudos descritivos, conforme Martins (2002), procuram descrever características de determinada população, estabelecendo relações entre variáveis e fatos.

O termo "perfil" é empregado com a finalidade de expressar as características que dão o contorno às redes sociais de cooperação. Numa perspectiva longitudinal de análise, exploraramse 9 edições do evento, operacionalmente agrupadas em 3 triênios (2001-2003; 2004-2006 e 2007-2009), possibilitando, assim, a visualização de transformações ocorridas no período estuda- do. Ressalte-se que tais triênios coincidem com aqueles que serviram de base para as avaliações dos Programas de Pós-Graduação Stricto Sensu periodicamente realizadas por parte da CAPES.

$\mathrm{O}$ universo estudado é representado pelos 882 artigos veiculados no período compreendido pela análise, nos quais participaram 1.120 pesquisadores. $\mathrm{O}$ estudo abrange todas as áreas temáticas do congresso. Em suas 3 primeiras edições, o evento não segregou a produção científica proveniente da Graduação e da Pós-Graduação; ocasião em que ocorria no formato de Seminário. Assim, a figura do Congresso USP de Controladoria e Contabilidade passou a existir a partir de 2004: específica para a produção científica originária da Pós-Graduação. Nessa data, teve início o Congresso de Iniciação Científica (Produção Científica da Graduação) que não faz parte do escopo da presente pesquisa. 
Os dados foram extraídos por meio de análise documental dos 882 artigos e tabulados em planilha eletrônica do software Microsoft Excel $^{\circledR}$. Os autores foram, em sua maioria, identificados pelos nomes indicados na autoria e coautoria dos artigos; ainda assim, houve casos em que se recorreu à Plataforma Lattes do $\mathrm{CNPq}$ para esclarecimento de algumas inconsistências, bem como para controlar o caso homônimo: Ricardo Lopes Cardoso. A projeção das redes sociais e os cálculos de suas propriedades estruturais deram-se por meio da utilização do software UCINET 6.0 (BORGATTI; EVERETT; FREEMAN, 2002).

Quanto aos procedimentos operacionais relativos às redes, as relações foram estruturadas a partir de uma matriz simétrica, ou seja, se o ator x está ligado ao ator y, automaticamente o y está ligado ao x. Para a contagem de laços, considerou-se o número de atores com os quais cada autor colaborou. A constituição das redes deuse em conformidade com o critério utilizado por Moody (2004), que assumiu que dois atores formam um componente na ocasião em que escrevem um artigo em conjunto, independen- temente da forma de apresentação de seus nomes (autor X coautor). Em termos práticos, os autores que cooperam no desenvolvimento de um artigo formam uma sub-rede que pode ser ampliada à medida que ocorre o envolvimento desses autores com outros pesquisadores.

A Figura 1 exibe a forma de estruturação de redes empregadas neste estudo. Na parte superior, tem-se uma representação esquemática de autores (quadrados) conectados aos seus respectivos artigos (círculos). A ilustração contempla autores que desenvolveram trabalhos isoladamente (A, B, C e D), bem como os demais pesquisadores que optaram pela perspectiva colaborativa. $\mathrm{Na}$ parte superior, à direta, tem-se o conjunto de atores conectados entre si e seus artigos. Na parte inferior, desprezam-se as informações relativas aos artigos, consideram-se apenas as coautorias. Tem-se, assim, a rede de colaboração resultante da simulação projetada. No caso de trabalhos de autoria única, os autores são ilustrados à parte da rede; os autores que trabalharam em pares, também, aparecem de forma isolada ( $\mathrm{E} \times \mathrm{F} ; \mathrm{G} \times \mathrm{H})$.

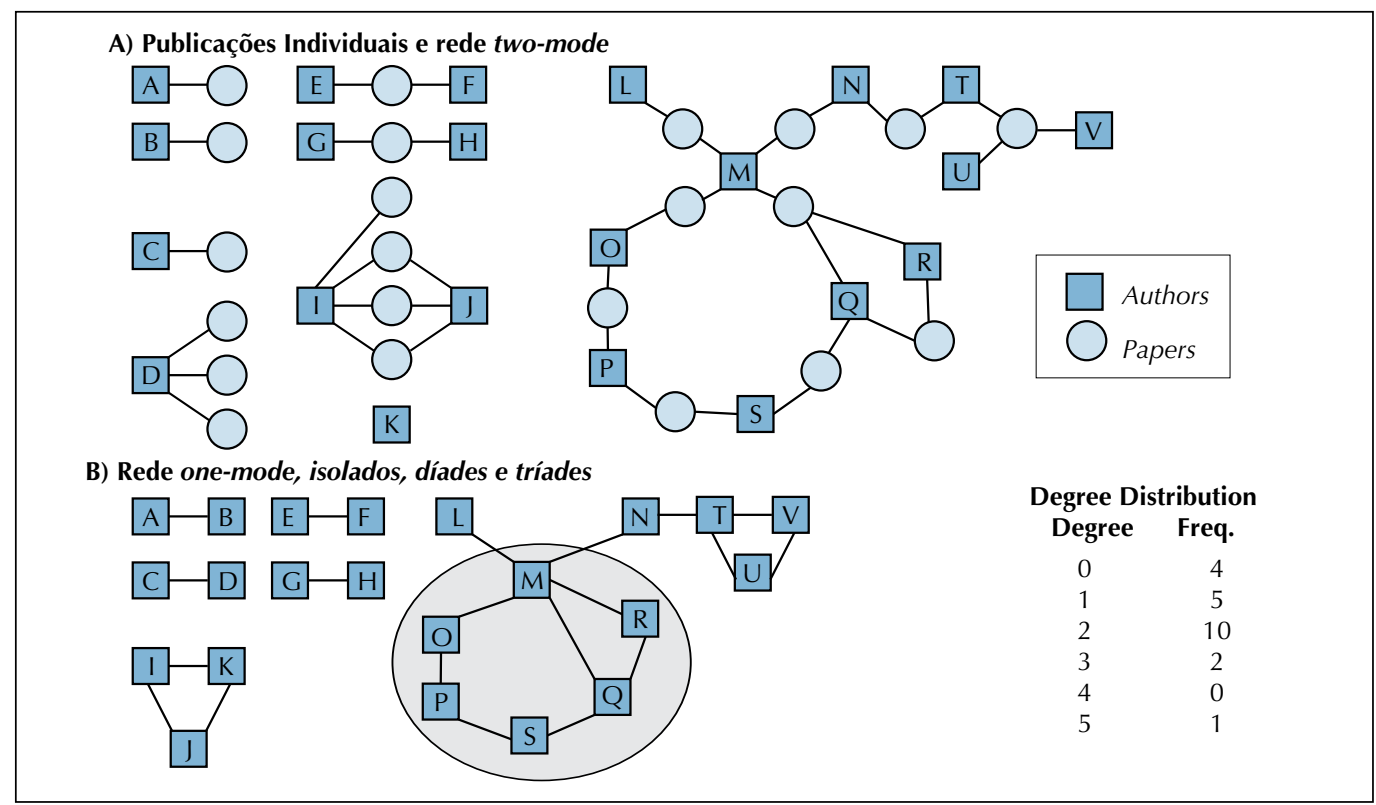

Figura 1 Construção das redes de cooperação 
No Quadro 1, estão reunidos os aspectos científica e elementos estruturais da rede), bem mapeados no estudo (indicadores da produção como as fontes que respaldam essas escolhas.

Quadro 1 Definições Operacionais da Pesquisa

\begin{tabular}{|c|c|c|}
\hline \multicolumn{2}{|c|}{ ASPECTOS MAPEADOS } & FONTE \\
\hline \multirow{6}{*}{ Indicadores da Produção Científica } & Número de Artigos Selecionados & \multirow{6}{*}{$\begin{array}{l}\text { Cardoso et al. (2005) } \\
\text { Nascimento, Junqueira e Martins } \\
\text { (2010) } \\
\text { Martins (2009) }\end{array}$} \\
\hline & Número de Artigos por Autor & \\
\hline & Número de Autores por Artigo & \\
\hline & Ano de Publicação & \\
\hline & Área Temática & \\
\hline & Autores Envolvidos & \\
\hline \multirow{4}{*}{ Elementos Estruturais da Rede } & Centralidade de Grau & \multirow{4}{*}{$\begin{array}{l}\text { Rossoni (2006) } \\
\text { Guarido Filho (2008) } \\
\text { Martins (2009) }\end{array}$} \\
\hline & Centralidade de Intermediação & \\
\hline & Densidade & \\
\hline & Componentes & \\
\hline
\end{tabular}

Considerou-se que há cooperação entre os atores quando da produção conjunta de um artigo científico, ocasião em que se estabelece uma relação. Assim, pressupõe-se que a estrutura de relacionamento é construída a partir da colaboração entre os atores envolvidos na produção de cada artigo científico, formativos de uma rede social de cooperação.
Ressalte-se que os termos parceria, cooperação e, ainda, colaboração são utilizados indistintamente ao longo da análise, indicativos da relação de coautoria verificada nas pesquisas estudadas. Em adição, saliente-se que a verificação dos fatores que induzem à perspectiva colaborativa não está contemplada pela proposta deste estudo.

\section{PERFIL DAS REDES DE COOPERAÇÃO CONFIGURADAS ENTRE OS PESQUISADORES}

As 9 edições do Congresso USP de Controladoria e Contabilidade [20012009] implicaram a divulgação de 882 artigos que envolveram a participação de
1.120 pesquisadores. A Tabela 1 detalha o volume anual de artigos selecionados em cada uma das áreas temáticas das edições do evento.

Tabela 1 Volume anual de artigos selecionados por área temática

\begin{tabular}{l|c|c|c|c|c|c|c|c|c|c}
\hline ÁREA TEMÁTICA & $\mathbf{0 1}$ & $\mathbf{0 2}$ & $\mathbf{0 3}$ & $\mathbf{0 4}$ & $\mathbf{0 5}$ & $\mathbf{0 6}$ & $\mathbf{0 7}$ & $\mathbf{0 8}$ & $\mathbf{0 9}$ & TOTAL \\
\hline Contabilidade de Custos & 14 & 26 & & & & & & & & 40 \\
\hline Contabilidade Geral & 8 & 12 & & & & & & & & 20 \\
\hline Controladoria & 30 & 10 & & & & & & & & 40 \\
\hline Educação, Profissão e Pesquisa Contábil & 7 & 7 & & & & & & & & 14 \\
\hline Temas Emergentes & 15 & 30 & 23 & 25 & 34 & 37 & & & & 164 \\
\hline Pesquisa e Ensino em Contabilidade & & & 11 & 5 & 2 & 14 & & & & 32 \\
\hline Contabilidade para Usuários Externos & & & 20 & 16 & 18 & 32 & 44 & 29 & 23 & 182 \\
\hline
\end{tabular}


continuação

\begin{tabular}{l|c|c|c|c|c|c|c|c|c|c}
\hline ÁREA TEMÁTICA & $\mathbf{0 1}$ & $\mathbf{0 2}$ & $\mathbf{0 3}$ & $\mathbf{0 4}$ & $\mathbf{0 5}$ & $\mathbf{0 6}$ & $\mathbf{0 7}$ & $\mathbf{0 8}$ & $\mathbf{0 9}$ & TOTAL \\
\hline Controladoria e Contabilidade Gerencial & & & 33 & 25 & 23 & 39 & 40 & 21 & 24 & 205 \\
\hline Mercados Financeiro, de Crédito e de Capitais & & & 14 & 29 & 23 & 28 & 20 & 20 & 8 & 142 \\
\hline Educação e Pesquisa em Contabilidade & & & & & & & 14 & 10 & 8 & 32 \\
\hline Atuária & & & & & & & 2 & 4 & 5 & 11 \\
\hline Total Anual & 74 & 85 & 101 & 100 & 100 & 150 & 120 & 84 & 68 & 882 \\
\hline TOTAL TRIENAL & \multicolumn{2}{|c|}{ 260 ARTIGOS } & \multicolumn{2}{|c|}{350 ARTIGOS } & \multicolumn{2}{|c|}{272 ARTIGOS } & $\mathbf{8 8 2}$ \\
\hline
\end{tabular}

Conforme a Tabela 1, as temáticas discutidas nos dois primeiros anos do evento sinalizam que, à época, a pesquisa contábil apresentava contornos distintos daquele atualmente vigente. Não era abordada a temática Contabilidade Gerencial, mas Contabilidade de Custos - mais restrita - e Controladoria. Era disponibilizada uma linha relativamente ampla denominada de Contabilidade Geral e contava-se com espaços para pesquisas que versassem sobre Temas Emergentes e Educação, Profissão e Pesquisa Contábil.

Paralelamente às mudanças de caráter estrutural do evento (volume de artigos aceitos e áreas temáticas), a análise dos dados coletados revela que, ao longo do período 20012009, houve alterações na forma como os pesquisadores cooperaram. O primeiro triênio do evento caracterizou-se pela concentração de esforços individuais de pesquisa (32\%), representando quase um terço dos artigos submetidos e aceitos. Contudo, o desenvolvimento de estudos em parceria entre dois pesquisadores, igualmente, foi expressivo (30\%).

No segundo triênio, houve predomínio de artigos com dois autores e expressiva redução da quantidade de artigos selecionados decorrentes de pesquisas de autoria única. Por fim, no terceiro triênio, a realização de estudos, a partir da perspectiva colaborativa, ou seja, com mais de um autor, mostrou-se a prática mais comum, tendo sido verificada em mais de $91 \%$ do volume de publicações. A Tabela 2 detalha a quantidade de artigos selecionados nos três triênios do evento em função do número de autores envolvidos em cada pesquisa e o seu respectivo percentual relativo ao total de artigos veiculados a cada três anos. De forma complementar, tem-se um agrupamento do período 2001-2009.

Tabela 2 Número de autores por artigo

\begin{tabular}{|c|c|c|c|c|c|c|c|c|}
\hline No DE AUTORES & \multicolumn{2}{|c|}{ 2001-2003 } & \multicolumn{2}{|c|}{ 2004-2006 } & \multicolumn{2}{|c|}{ 2007-2009 } & \multicolumn{2}{|c|}{ 2001-2009 } \\
\hline 1 autor & 84 & $32,31 \%$ & 48 & $13,71 \%$ & 22 & $8,09 \%$ & 154 & $17,46 \%$ \\
\hline 2 autores & 78 & $30,0 \%$ & 141 & $40,29 \%$ & 93 & $34,19 \%$ & 312 & $35,37 \%$ \\
\hline 3 autores & 48 & $18,46 \%$ & 89 & $25,43 \%$ & 92 & $33,82 \%$ & 229 & $25,96 \%$ \\
\hline 4 autores & 48 & $18,46 \%$ & 72 & $20,57 \%$ & 65 & $23,9 \%$ & 185 & 20,98 \\
\hline 5 autores & 2 & $0,77 \%$ & 0 & $0,0 \%$ & 0 & $0,0 \%$ & 2 & $0,23 \%$ \\
\hline TOTAL & \multicolumn{2}{|c|}{260 artigos } & \multicolumn{2}{|c|}{350 artigos } & \multicolumn{2}{|c|}{272 artigos } & \multicolumn{2}{|c|}{882 artigos } \\
\hline
\end{tabular}

Em linhas gerais, os pesquisadores com artigos aceitos no Congresso estudado parecem ter modificado sua postura no que diz respeito à formação de parcerias, estando mais receptivos à ideia de desenvolvimento conjunto de investigações. Essa tendência mostra-se convergente aos achados de Englebrecht, Hanke e Kuang (2008), que constataram aumento significativo da colaboração manifestada na forma de coautoria em journals contábeis no período de 1979 a 2004. Desse modo, os achados indicam que o for- 
mato de estruturação de coautoria praticado por pesquisadores brasileiros mostra-se alinhado à prática internacional constatada por Englebrecht, Hanke e Kuang (2008).

As exigências de publicação interpostas pela CAPES aos Programas de PósGraduação (PPG) podem sugerir uma das explicações para o aumento da cooperação entre os autores. A pontuação atribuída aos PPGs, nesse quesito, considera as pesquisas publicadas pelos corpos docente e discente, sendo que atribui pontuação integral no caso de autores e coautores do segundo grupo, enquanto que para o primeiro, os pontos são divididos entre os docentes participantes das publicações. Assim sendo, verifica-se que o aumento da colaboração configura-se como uma das exigências da CAPES, visto que quanto maior a cooperação entre autores e coautores, maior o êxito dos PPGs na avaliação da realizada pela institução.
Contudo, apesar desse esforço de fazer pesquisa mediante o envolvimento de mais de um pesquisador, a maioria dos atores $(64,4 \%)$ colaborou em apenas 1 artigo; em outras palavras, 721 dos 1.120 atores identificados no universo pesquisado publicaram apenas 1 artigo durante os 9 anos do evento. Resultado muito semelhante foi encontrado por Acedo et al. (2006) que, ao explorarem o campo de estudos organizacionais, constataram que pouco mais de $65 \%$ dos autores abrangidos pela análise publicaram apenas um único estudo. Essa estratificação da produção científica é matematicamente representada pela Lei de Lotka. Segundo a referida lei, o número de autores que publicam uma única vez corresponde, em média, a 60\% de uma amostra, havendo, também, tendência de uma forte concentração de publicações em um número muito pequeno de autores. A Tabela 3 evidencia informações acerca do número de artigos por autor.

Tabela 3 Número de Artigos por Autor

\begin{tabular}{l|c|c|c|c|c|c|c|c}
\hline AUTORES COM & \multicolumn{2}{|c|}{$\mathbf{2 0 0 1 - 2 0 0 3}$} & \multicolumn{2}{|c|}{$2004-2006$} & \multicolumn{2}{c|}{$\mathbf{2 0 0 7 - 2 0 0 9}$} & \multicolumn{2}{c}{$\mathbf{2 0 0 1 - 2 0 0 9}$} \\
\hline 1 artigo selecionado & 277 & $71,03 \%$ & 372 & $68,38 \%$ & 325 & $67,43 \%$ & 721 & $64,38 \%$ \\
\hline 2 artigos selecionados & 68 & $17,44 \%$ & 91 & $16,73 \%$ & 91 & $18,88 \%$ & 165 & $14,73 \%$ \\
\hline 3 artigos selecionados & 26 & $6,67 \%$ & 40 & $7,35 \%$ & 40 & $8,30 \%$ & 97 & $8,66 \%$ \\
\hline 4 artigos selecionados & 5 & $1,28 \%$ & 20 & $3,68 \%$ & 17 & $3,53 \%$ & 42 & $3,75 \%$ \\
\hline 5 artigos selecionados & 7 & $1,79 \%$ & 8 & $1,47 \%$ & 5 & $1,04 \%$ & 28 & $2,50 \%$ \\
\hline 6 artigos selecionados & 6 & $1,54 \%$ & 5 & $0,92 \%$ & 4 & $0,83 \%$ & 22 & $1,96 \%$ \\
\hline 7 ou mais artigos selecionados & 1 & $0,26 \%$ & 8 & $1,47 \%$ & & & 45 & $4,02 \%$ \\
\hline TOTAL & $\mathbf{3 9 0}$ AUTORES & $\mathbf{5 4 4}$ AUTORES & $\mathbf{4 8 2}$ AUTORES & $\mathbf{1 . 1 2 0}$ AUTORES \\
\hline
\end{tabular}

$\mathrm{Na}$ Tabela 4 estão reunidos os dados sobre a estrutura de relações firmadas entre os pesquisadores em cada um dos triênios explorados. Constataram-se algumas mudanças na configuração da rede de coautoria. Houve aumento no número de artigos selecionados entre o $1^{\circ}$ e $2^{\circ}$ triênio; porém, no $3^{\circ}$ triênio, esse volume apresentou redução em relação ao período anterior. O número de atores presentes, também, acompanhou essas variações, contudo, as médias de autores por artigo e de laços por autor mostraram-se crescentes em todos os triênios, indicando, assim, postura mais receptiva à produção conjunta de artigos científicos. O procedimento adotado para a contagem dos laços deve desprezar eventuais repetições de parceiros e os resultados da análise sugerem que os pesquisadores do campo de Controladoria e Contabilidade têm ampliado sua rede de contatos, manifestando envolvimento com maior número de parceiros.

Apesar do envolvimento gradativo de um maior número de pesquisadores, em média, 
por artigos selecionados e similarmente aos achados de Acedo et al. (2005), a rede de cooperação mostrou-se fragmentada em todos os triênios analisados, conforme indica o número de componentes formados (Tabela 4). Caracterizados como uma espécie de subredes, os componentes indicam o número de agrupamentos isolados constituídos no triênio. Como decorrência de tal formato de cooperação, inúmeros pesquisadores podem estar sendo privados do acesso às informações compartilhadas em outras sub-redes; consequentemente é possível que o formato esteja inibindo a evolução do campo de pesquisa em Controladoria e Contabilidade. A redução do total de componentes formados nos três triênios analisados é sugere de que a conversação entre os atores esteja sendo incrementada, o que é bastante positivo. Contudo, o número de autores com artigos aceitos nos $1^{\circ}, 2^{\circ}$ e $3^{\circ}$ triênios que participaram das maiores sub-redes ( $11,03 \%, 29,04 \%$ e $26,76 \%$, respectivamente) mostrou-se inferior às evidências obtidas por Acedo et al. (2005) na área de estudos organizacionais, que, apesar de terem identificado poucos componentes constituídos por um grande número de autores, constataram a reunião de pouco mais de $45 \%$ dos pesquisadores no principal componente (que reuniu o maior número de autores).

Tabela 4 Dados da Estrutura de Relações

\begin{tabular}{l|c|c|c}
\hline & $\mathbf{2 0 0 1 - 2 0 0 3}$ & $\mathbf{2 0 0 4 - 2 0 0 6}$ & $\mathbf{2 0 0 7 - 2 0 0 9}$ \\
\hline Número de Laços & 955 & 1496 & 1524 \\
\hline Número de Autores & 390 & 544 & 482 \\
\hline Média de Laços por Autor & 2,45 & 2,75 & 3,16 \\
\hline Número de Componentes & 116 & 105 & 80 \\
\hline Tamanho do Componente Principal & 43 & 158 & 129 \\
\hline Tamanho do 2o Maior Componente & 38 & 51 & 48 \\
\hline Tamanho do 3o Maior Componente & 16 & 19 & 17 \\
\hline Autores Isolados & 52 & 24 & 12 \\
\hline Densidade da Rede & 0,0063 & 0,0051 & 0,0066 \\
\hline
\end{tabular}

Ainda com relação à Tabela 4 , cumpre observar que a rede de cooperação apresentou baixa densidade em todos os períodos do triênio. Contrariamente às possíveis conjecturas sugeridas pela média de laços por autor $(2,45$; $2,75$ e 3,16$)$, a baixa densidade da rede $(0,0063$; $0,0051$ e 0,0066$)$ pode sinalizar uma limitação do grupo de pesquisadores analisado, uma vez que essa métrica evidencia que a intensidade da interação entre os atores foi pouco incrementada ao longo do tempo (MELLO; CRUBELLATE; ROSSONI, 2010), ou seja, tendo em vista o número de autores do universo analisado, o volume de relações que poderiam ocorrer é muito superior ao que de fato está constituído. Conforme Guarido Filho (2008, p. 138), “[...] isoladamente, esse indicador aponta a baixa cooperação entre os autores e o limitado compar- tilhamento de ideias entre eles em nível global". Na sequência são discutidos os resultados relativos a cada um dos 3 triênios do Congresso.

\subsection{Congresso USP de Controladoria e Contabilidade no triênio 2001- 2003}

A Figura 2 ilustra a estrutura de relacionamento entre os pesquisadores com artigos aceitos no triênio 2001-2003 do Congresso USP de Controladoria e Contabilidade. Os nós representam os atores e as linhas indicam as relações firmadas entre eles, manifestadas na forma de coautoria(s) de artigo(s) científico(s). Estão nominados os cincos autores com maior centralidade de intermediação. O tamanho dos nós foi dimensionado com base no número de laços de cada um 
dos atores, ou seja, considerou-se o número de parceiros com que cada ator se envolveu para o desenvolvimento da produção científica veiculada no triênio. Verificou-se a presença de 390 pesquisadores distintos nos 260 artigos selecionados, ou seja, uma média de 1,5 autores por artigo; contudo, 52 pesquisadores estiveram isolados.

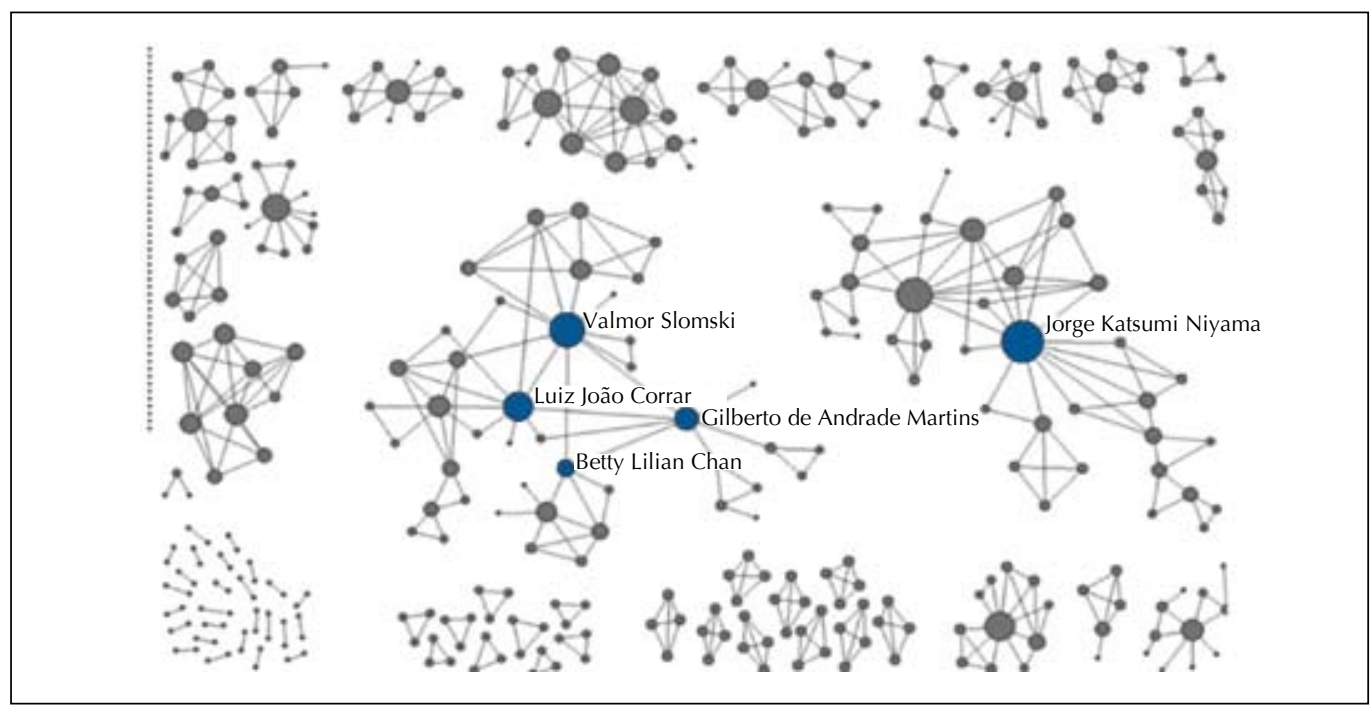

Figura 2 Rede de cooperação entre pesquisadores no triênio 2001-2003

Conforme a Tabela 4, a estrutura das relações firmadas no primeiro triênio foi constituída por 116 componentes. Desses, 52 (alinhados à esquerda) contaram com um autor ( $44,83 \%$ dos componentes) e 26 foram formados por 2 pesquisadores (parte inferior esquerda - 22,41\% dos componentes). As duas maiores sub-redes (componentes - ilustrados no centro) reuniram 43 e 38 atores. Jorge Nyama, Valmor Slomski, Gilberto Martins, Betty Chan e Luiz Corrar foram, nessa ordem, os autores mais centrais em termos de intermediação. $\mathrm{O}$ escore de centralidade desses autores indica que puderam agenciar o repasse das informações às quais tiveram acesso, visto que acumularam capital social por meio de acessos sociais e o transmitiram às suas redes de contatos mediante o relacionamento existente entre os atores e a habilidade de repasse das informações a serem reproduzidas. A seguir, a Tabela 5 reúne os autores com mais de 3 artigos veiculados no período 2001-2003
Tabela 5 Autores mais prolíficos no triênio 2001-2003

\begin{tabular}{l|c|c|c|c}
\hline AUTORES & $\mathbf{0 1}$ & $\mathbf{0 2}$ & $\mathbf{0 3}$ & $\mathbf{T}$ \\
\hline Rubens Fama & 1 & 4 & 2 & 7 \\
\hline César Augusto Tibúrcio Silva & 1 & 2 & 3 & 6 \\
\hline Gilberto de Andrade Martins & 1 & & 5 & 6 \\
\hline Ilse Maria Beuren & 1 & 3 & 2 & 6 \\
\hline Jorge Katsumi Niyama & 1 & 5 & & 6 \\
\hline Luiz Carlos Miranda & 1 & 4 & 1 & 6 \\
\hline Valmor Slomski & & & 6 & 6 \\
\hline Ana Paula Ferreira da Silva & 2 & 2 & 1 & 5 \\
\hline André Moura Cintra Goulart & 2 & 2 & 1 & 5 \\
\hline Aridelmo J. C. Teixeira & & 1 & 4 & 5 \\
\hline Érica Xavier de Souza & 2 & 2 & 1 & 5 \\
\hline José Ricardo M. de Siqueira & 2 & 1 & 2 & 5 \\
\hline Luiz João Corrar & & 1 & 4 & 5 \\
\hline Maísa de Souza Ribeiro & & & 5 & 5 \\
\hline Antônio A. de Sá Freire Filho & 2 & 1 & 1 & 4 \\
\hline Célia Maria Braga Carneiro & 2 & 2 & & 4 \\
\hline Marcelo Seido Nagano & 2 & 2 & & 4 \\
\hline Masayuki Nakagawa & 3 & & 1 & 4 \\
\hline Reinaldo Guerreiro & & 1 & 3 & 4 \\
\hline
\end{tabular}


Quanto às áreas temáticas pesquisadas pelos autores mais prolíficos (Tabela 5), identificou-se maior interesse por Temas Emergentes, seguido de Controladoria e Contabilidade Gerencial (que envolvia, à época, as áreas de Contabilidade de Custos e Controladoria). Saliente-se que 3 dos 19 pesquisadores elencados na Tabela 5 tiveram artigos aceitos em todas as áreas temáticas do evento. Conforme indica a Tabela 5, no triênio analisado, houve 7 pesquisadores com mais de 5 artigos selecionados. A análise comparativa entre a centralidade de intermediação e o volume de artigos publicados por cada ator indica que, possivelmente, a prolificidade de tais pesquisadores esteja condicionada pelas posições que ocuparam na rede (todos são atores intermediadores). Ressalte-se, ainda, que, comparativamente aos demais atores constituintes do campo, esses 7 pesquisadores estiveram conectados a um número mais significativo de parceiros (destacaram-se no número de laços relacionais), conforme indica a Tabela 6, que nomina os pesquisadores com mais de 6 laços.

Tabela 6 Autores com mais de 6 laços relacionais no triênio 2001-2003

\begin{tabular}{l|c}
\hline AUTORES & LAÇOS \\
\hline Jorge Katsumi Niyama & 14 \\
\hline César Augusto Tibúrcio Silva & 12 \\
\hline Valmor Slomski & 11 \\
\hline Aridelmo J. C. Teixeira & 10 \\
\hline Ilse Maria Beuren & 9 \\
\hline Luiz Carlos Miranda & 9 \\
\hline Luiz João Corrar & 9 \\
\hline Umbelina C. Teixeira Lagioia & 9 \\
\hline Antônio A. de Sá Freire Filho & 8 \\
\hline Maria N. Monteiro Pessoa & 8 \\
\hline Ana Paula Ferreira da Silva & 7 \\
\hline Érica Xavier de Souza & 7 \\
\hline Flávio Donizete Batistella & 7 \\
\hline Gilberto de Andrade Martins & 7 \\
\hline Maísa de Souza Ribeiro & 7 \\
\hline Marcelo Seido Nagano & 7 \\
\hline Rubens Famá & 7 \\
\hline Silverio A. D. Nascimento & 7 \\
\hline
\end{tabular}

Confirmando a importância da formação de parcerias e da estruturação de redes de pesquisas, a análise comparativa das Tabelas 5 e 6 indica que os autores que se destacaram no volume de artigos publicados, também, apresentaram os maiores números de laços relacionais. Ainda assim, mesmo que dois componentes tenham reunido $20,77 \%$ dos autores com artigos aceitos no primeiro triênio do Congresso USP de Controladoria e Contabilidade, a rede de cooperação apresentou baixa densidade $(0,0063)$, indicando que as conexões presentes entre o grupo estiveram muito aquém do número de relações possíveis.

Adicionalmente à exploração do formato das conexões, verificou-se que houve predominância de laços fortes. Assim, tem-se que a preferência de organização no primeiro triênio se deu mediante o contato direto entre parceiros. Apesar dessa preferência, conexões indiretas (laços fracos), também, foram constatadas, proporcionando, assim, que alguns pesquisadores assumissem o papel de intermediadores na rede de cooperação. A seguir, são apresentados e discutidos os resultados relativos ao segundo triênio do Congresso.

\subsection{Congresso USP de Controladoria e Contabilidade no triênio 2004- 2006}

A Figura 3 ilustra a representação estrutural da rede de cooperação configurada no período 2004-2006 que implicou envolvimento de 544 pesquisadores na produção de 350 artigos. O número de atores isolados que no período 2001-2003 foi de 52 caiu para 24 no $2^{\circ}$ triênio, ou seja, parcela relativamente menor de autores realizou pesquisas sem parceiros. De forma similar às constatações do $1^{\circ}$ triênio, predominaram conexões fortes. 


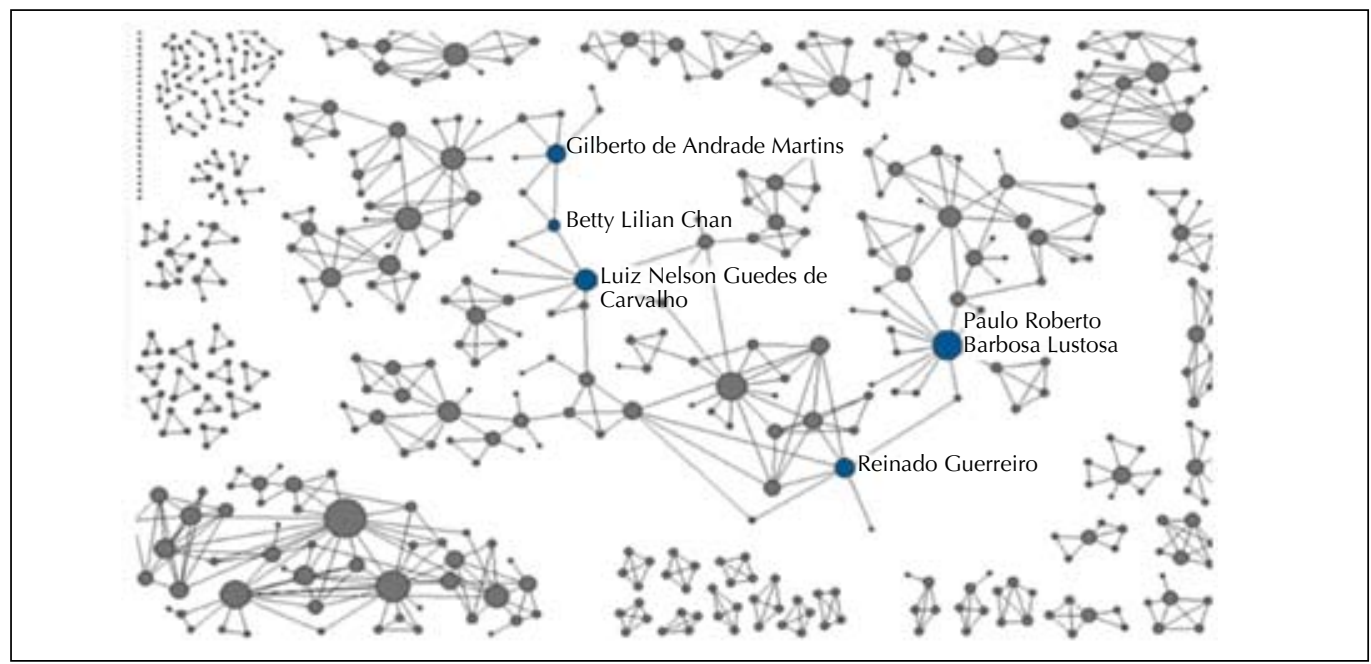

Figura 3 Rede de cooperação entre pesquisadores no triênio 2004-2006

Conforme a Figura 3, o segundo triênio foi caracterizado pela presença de 105 sub-redes; os maiores componentes envolveram: 158 (no centro da figura); 51 (no canto inferior esquerdo) e 19 (no canto superior direito) pesquisadores. Luiz Carvalho, Paulo Lustosa, Reinaldo Guerreiro, Betty Chan e Gilberto Martins apresentaram os maiores escores de centralidade de intermediação no período. A ilustração da rede de cooperação configurada no período 2004-2006 permite visualizar que os 5 atores mais centrais, em termos de intermediação, integraram o mesmo componente.

Na Tabela 7, explora-se o quesito prolificidade, com indicação dos pesquisadores com mais de 3 artigos selecionados no segundo triênio. Constatou-se que houve aumento do número de autores com maior quantidade de artigos selecionados. No triênio 2001-2003, houve 19 pesquisadores com mais de 3 artigos selecionados (Tabela 5) e, no segundo triênio, esse número aumentou para 41 pesquisadores (Tabela 7).
Tabela 7 Autores mais prolíficos no triênio 2004-2006

\begin{tabular}{|c|c|c|c|c|}
\hline AUTORES & 04 & 05 & 06 & $\mathbf{T}$ \\
\hline Paulo R. Barbosa Lustosa & 4 & 3 & 3 & 10 \\
\hline César A. Tibúrcio Silva & 2 & 3 & 3 & 8 \\
\hline Fábio Moraes da Costa & 3 & 2 & 3 & 8 \\
\hline Luiz João Corrar & 6 & 1 & 1 & 8 \\
\hline Alberto S. Matsumoto & 3 & 2 & 2 & 7 \\
\hline Antonio Lopo Martinez & 3 & 2 & 2 & 7 \\
\hline Maísa de Souza Ribeiro & 5 & & 2 & 7 \\
\hline Marcelle Colares Oliveira & 3 & 1 & 3 & 7 \\
\hline Aridelmo J. C. Teixeira & 3 & 2 & 1 & 6 \\
\hline Ilse Maria Beuren & 2 & 2 & 2 & 6 \\
\hline Luis S. Ribeiro dos Santos & 2 & 2 & 2 & 6 \\
\hline Otávio Ribeiro de Medeiros & 5 & 1 & & 6 \\
\hline Valcemiro Nossa & 4 & 1 & 1 & 6 \\
\hline César Medeiros Cupertino & 2 & 1 & 2 & 5 \\
\hline Flávia Zóboli Dalmácio & 1 & 3 & 1 & 5 \\
\hline Gilberto de Andrade Martins & 2 & 1 & 2 & 5 \\
\hline José Odálio dos Santos & 3 & & 2 & 5 \\
\hline L. Nelson G. de Carvalho & 3 & 1 & 1 & 5 \\
\hline Pablo Rogers & 2 & 1 & 2 & 5 \\
\hline Paulo Sergio Ceretta & 3 & 1 & 1 & 5 \\
\hline Valmor Slomski & 2 & 1 & 2 & 5 \\
\hline Alexsandro Broedel Lopes & 1 & 2 & 1 & 4 \\
\hline Alfredo Sarlo Neto & 1 & 1 & 2 & 4 \\
\hline Auster Moreira Nascimento & & 1 & 3 & 4 \\
\hline
\end{tabular}




\begin{tabular}{l|c|c|c|c}
\hline continuação & $\mathbf{0 4}$ & $\mathbf{0 5}$ & $\mathbf{0 6}$ & $\mathbf{T}$ \\
\hline EuTORES & 2 & & 2 & 4 \\
\hline Ernani Ott & & 2 & 2 & 4 \\
\hline Fernanda Fernandes Rodrigues & 2 & 1 & 1 & 4 \\
\hline Gilmar Ribeiro de Mello & & 1 & 3 & 4 \\
\hline Idália A. Cangussú Rezende & 1 & 2 & 1 & 4 \\
\hline Ivam Ricardo Peleias & 2 & 1 & 1 & 4 \\
\hline João E. Prudêncio Tinoco & 1 & 2 & 1 & 4 \\
\hline José Elias Feres de Almeida & & 2 & 2 & 4 \\
\hline José Francisco Ribeiro Filho & 3 & 1 & & 4 \\
\hline Josedilton Alves Diniz & 2 & 1 & 1 & 4 \\
\hline Luiz Henrique Lima Faria & & 2 & 2 & 4 \\
\hline Marcelo Moll Brandão & & 2 & 2 & 4 \\
\hline Márcia de Luca & & 1 & 3 & 4 \\
\hline Patrícia de Souza Costa & 1 & 1 & 2 & 4 \\
\hline Reinaldo Guerreiro & 2 & 1 & 1 & 4 \\
\hline Romualdo Douglas Colauto & 1 & 1 & 2 & 4 \\
\hline Welington Rocha & 1 & & 3 & 4 \\
\hline
\end{tabular}

A área temática de Pesquisa e Ensino em Contabilidade foi a menos recorrente dentre os autores mais prolíficos (Tabela 7). O interesse desse grupo mostrou-se mais inclinado para Temas Emergentes, seguido de Contabilidade para Usuários Externos; Mercados Financeiro, de Crédito e de Capitais e, por fim, Controladoria e Contabilidade Gerencial.

Mesmo com a redução da densidade da rede de pesquisadores $(0,0063$ no primeiro triênio e 0,0051 no segundo triênio), o número médio de laços por autor aumentou de 2,45 para 2,75. A Tabela 8 indica o número de laços firmados pelos autores que se envolveram com mais de 6 parceiros. Similarmente ao aumento do número de pesquisadores com mais de 3 publicações (primeiro triênio $X$ segundo triênio), o número de autores com mais de 6 parceiros aumentou em 12 (número absoluto de pesquisadores). De modo similar às constatações relativas ao primeiro triênio, os autores mais prolíficos foram os que apresentaram o maior número de parceiros (Tabela $7 X$ Tabela 8 ); 25 dos 30 autores que se envolveram com mais de 6 parceiros foram, também, destaques de prolificidade.
Tabela 8 Autores com mais de 6 laços relacionais no triênio 2004-2006

\begin{tabular}{|c|c|}
\hline AUTORES & LAÇOS \\
\hline Fábio Moraes da Costa & 18 \\
\hline Valcemiro Nossa & 14 \\
\hline Aridelmo J. C. Teixeira & 13 \\
\hline Luiz João Corrar & 13 \\
\hline Paulo R. Barbosa Lustosa & 12 \\
\hline Marcelle Colares Oliveira & 11 \\
\hline Ivam Ricardo Peleias & 10 \\
\hline Luis S. Ribeiro dos Santos & 10 \\
\hline Maísa de Souza Ribeiro & 10 \\
\hline César A. Tibúrcio Silva & 9 \\
\hline Ilse Maria Beuren & 9 \\
\hline José Francisco Ribeiro Filho & 9 \\
\hline Josedilton Alves Diniz & 9 \\
\hline Alberto S. Matsumoto & 8 \\
\hline Antônio Artur de Souza & 8 \\
\hline Flávia Zóboli Dalmácio & 8 \\
\hline José Elias Feres de Almeida & 8 \\
\hline L. Nelson Guedes de Carvalho & 8 \\
\hline Marcelo Moll Brandão & 8 \\
\hline Márcia de Luca & 8 \\
\hline Sandra Maria dos Santos & 8 \\
\hline Alfredo Sarlo Neto & 7 \\
\hline Andson Braga de Aguiar & 7 \\
\hline Carlos Alberto Pereira & 7 \\
\hline Ernani Ott & 7 \\
\hline Fábio Frezatti & 7 \\
\hline Idália A. Cangussú Rezende & 7 \\
\hline Luiz Henrique Lima Faria & 7 \\
\hline Pablo Rogers & 7 \\
\hline Reinaldo Guerreiro & 7 \\
\hline
\end{tabular}

Analisando-se, conjuntamente, a Figura 3 e as Tabelas 7 e 8, têm-se algumas considerações importantes. Verificou-se que 5 dos 8 autores que obtiveram mais de 6 artigos selecionados (Tabela 7 ) integraram o componente principal da rede de cooperação estruturada no segundo triênio; são eles: Paulo Lustosa, César Silva, Luiz Corrar, Maísa Ribeiro e Marcelle Oliveira. No que tange à posição ocupada por esses 
5 pesquisadores, todos assumiram algum grau de centralidade de intermediação do fluxo de informações entre seus parceiros; todos os 5 ficaram classificados entre os 20 autores que apresentaram os maiores escores de intermediação. Já os outros 3 pesquisadores que também obtiveram mais de 6 artigos veiculados no período (Fábio Costa, Alberto Matsumoto e Antonio Martinez) integraram sub-redes diferentes. Com exceção de Antonio Martinez, os demais 7 pesquisadores, também, estão entre aqueles com maior número de parceiros.

Com relação à estabilidade da frequência dos pesquisadores constituintes do universo analisado, verificou-se que 120 dos 390 atores presentes no primeiro triênio permaneceram no período subsequente. Outros 270 não mais integraram o grupo de atores com artigos selecionados nas edições do triênio 2004-2006 do Congresso USP de Controladoria e Contabilidade e 424 novos pesquisadores passaram a integrar o grupo de atores que colaboraram para a manutenção do campo objeto de exploração neste estudo.

\subsection{Congresso USP de Controladoria e Contabilidade no triênio 2007- 2009}

A rede de cooperação configurada no terceiro triênio do Congresso USP de Controladoria e Contabilidade é ilustrada na Figura 4. Nesse período, foram publicados 272 artigos desenvolvidos por 482 pesquisadores. O número de atores isolados caiu 50\% em relação ao triênio imediatamente anterior (de 24 para 12 atores). Os pesquisadores organizaram-se em 80 sub-redes. Comparativamente ao segundo triênio, o maior componente constituído no período 2007-2009 envolveu número inferior de atores (129 pesquisadores). O número de relações firmadas (laços) aumentou cerca de $2 \%$ e a densidade da rede apresentou pequena melhora (de 0,0051 para 0,0066), porém o número de conexões firmadas em relação às ligações possíveis ainda foi baixo.

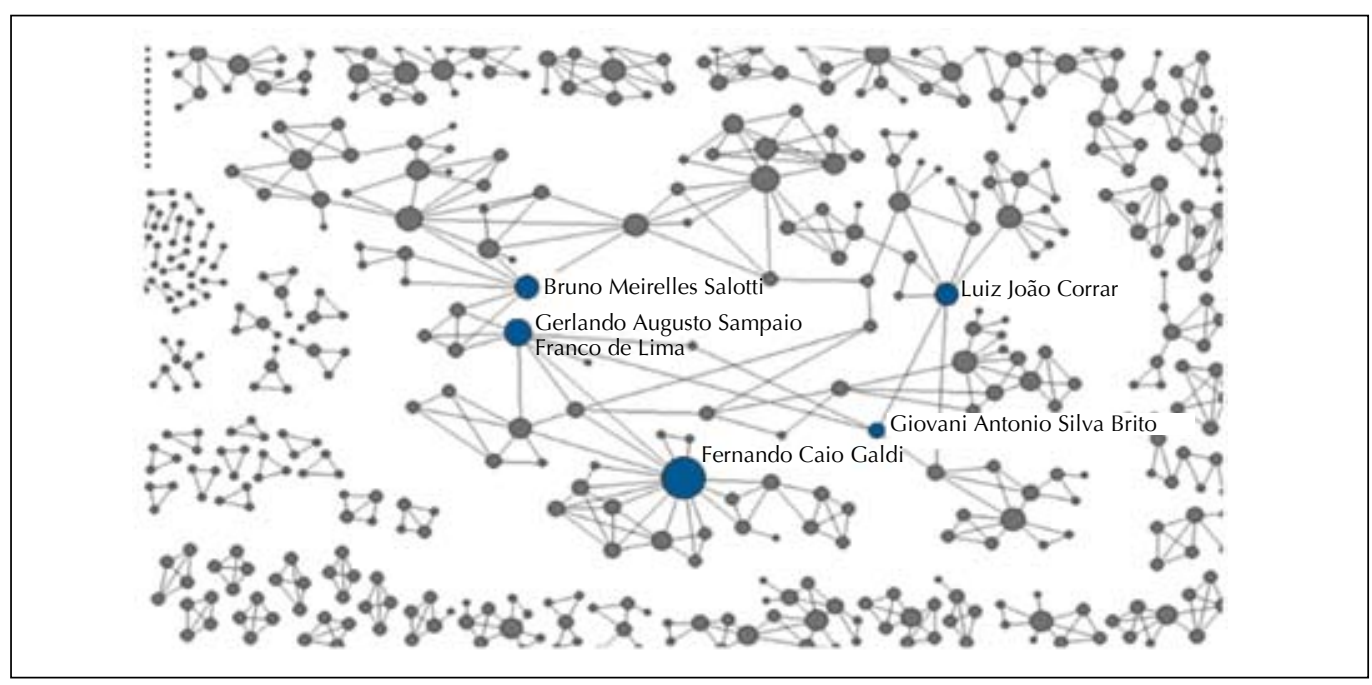

Figura 4 Rede de cooperação entre pesquisadores no triênio 2007-2009

Conforme ilustrado na Figura 4, Gerlando Lima, Bruno Salotti, Fernando Galdi, Luiz Corrar e Giovani Brito foram os 5 atores com maior escore de centralidade de intermediação da rede configurada no terceiro triênio. Todos eles integraram o componente principal (sub-rede ilus- trada no centro da Figura), constituído por 129 atores. $\mathrm{O}$ quadro teórico de referência de redes sociais de colaboração sugere que esses pesquisadores têm maior poder de agenciamento informacional, ou seja, podem decidir sobre o trânsito das informações que dispõem, escolhendo 
se desejam e com quem desejam compartilhar ideias para o desenvolvimento de novas pesquisas, achados que consideram relevantes, eventuais falhas detectadas em seus próprios estudos ou em trabalhos de terceiros etc.

Na Tabela 9, estão nominados os autores mais prolíficos do triênio 2007-2009 (com mais de 3 artigos selecionados). No período, houve redução do número de autores com destaque de prolificidade. No primeiro triênio, 4,87\% dos pesquisadores obtiveram mais de 3 artigos selecionados; no segundo triênio esse percentual aumentou para 7,54\% e no terceiro triênio 5,34\% dos atores (26 pesquisadores) atingiram esse nível de veiculação.

Tabela 9 Autores mais prolíficos no triênio 2007-2009

\begin{tabular}{|c|c|c|c|c|}
\hline AUTORES & $\mathbf{0 7}$ & 08 & 09 & $\mathbf{T}$ \\
\hline Emanuel R. Junqueira & 2 & 3 & 1 & 6 \\
\hline Fernando Caio Galdi & 2 & 3 & 1 & 6 \\
\hline Fernando Dal-Ri Murcia & 2 & 1 & 3 & 6 \\
\hline Ilse Maria Beuren & 2 & 3 & 1 & 6 \\
\hline Artur Roberto do Nascimento & & 3 & 2 & 5 \\
\hline Carlos Alberto Diehl & 1 & 1 & 3 & 5 \\
\hline Ernani Ott & 3 & 1 & 1 & 5 \\
\hline Gilberto de Andrade Martins & 2 & 2 & 1 & 5 \\
\hline Welington Rocha & 3 & 1 & 1 & 5 \\
\hline Adriano Mussa & 2 & 2 & & 4 \\
\hline Antonio Lopo Martinez & 1 & 1 & 2 & 4 \\
\hline Ariovaldo dos Santos & 1 & 1 & 2 & 4 \\
\hline Betty Lilian Chan & 2 & 2 & & 4 \\
\hline Carlos Alberto Pereira & 2 & 1 & 1 & 4 \\
\hline Fabiana Lopes da Silva & 2 & 2 & & 4 \\
\hline Flávio Leonel de Carvalho & 3 & & 1 & 4 \\
\hline Gerlando A. S. Franco de Lima & 2 & 1 & 1 & 4 \\
\hline Idalberto José das Neves Júnior & 3 & 1 & & 4 \\
\hline José Alonso Borba & 3 & & 1 & 4 \\
\hline José Carlos Tiomatsu Oyadomari & 2 & 1 & 1 & 4 \\
\hline Luiz João Corrar & 1 & 1 & 2 & 4 \\
\hline Marcelo A. da Silva Macedo & 1 & 2 & 1 & 4 \\
\hline Marcos Antonio de Souza & 1 & 1 & 2 & 4 \\
\hline Maria Thereza Pompa Antunes & 3 & 1 & & 4 \\
\hline Octavio R. de Mendonça Neto & 2 & 1 & 1 & 4 \\
\hline Ricardo Lopes Cardoso & 2 & 1 & 1 & 4 \\
\hline
\end{tabular}

A maioria dos pesquisadores constantes da Tabela 9 concentrou sua produção científica em duas das cinco áreas temáticas ofertadas pelo evento (Controladoria e Contabilidade Gerencial e Contabilidade para Usuários Externos). As pesquisas desses 26 atores estiveram, em sua maioria, distribuídas em mais de uma área temática. Apenas 6 atores desse grupo desenvolveram pesquisas concentradas em uma única linha temática. A combinação mais recorrente foi entre as linhas de Controladoria e Contabilidade Gerencial e Contabilidade para Usuários Externos, em outras palavras, 7 pesquisadores (dos listados na Tabela 9) tiveram seus artigos selecionados nessas duas áreas temáticas.

Os artigos de Educação e Pesquisa em Contabilidade foram desenvolvidos por pesquisadores envolvidos tanto com a linha de Controladoria e Contabilidade Gerencial (3 ocorrências), quanto com Contabilidade para Usuários Externos (3 ocorrências). Constatouse, ainda, que, considerando esse grupo de autores mais prolíficos, aqueles que manifestaram interesse pela área temática de Atuária não tiveram artigos selecionados na temática de Contabilidade para Usuários Externos ou Educação e Pesquisa.

No que tange às ligações estabelecidas, verificou-se que, no terceiro triênio, um número superior de pesquisadores apresentou mais de 6 laços relacionais (30 atores em 20042006 - 5,51\%; 38 em 2007-2009 - 7,88\%), conforme indica a Tabela 10. Esse formato de organização mostra-se bastante positivo, especialmente porque houve redução do número de atores presentes de um triênio para outro. A ampliação do número de conexões firmadas pelos autores configura-se como uma das alternativas à evolução de um campo científico, na medida em que proporciona a realização de trocas que tendem a incrementar o processo de pesquisa. Essa etapa parece estar sendo, intencional ou não intencionalmente, cumprida pelos pesquisadores envolvidos nas diversas edições do Congresso USP de Controladoria e Contabilidade. 
Tabela 10 Autores com mais de 6 laços relacionais no triênio 2004-2006

\begin{tabular}{|c|c|}
\hline AUTORES & LAÇOS \\
\hline Fernando Caio Galdi & 16 \\
\hline Emanuel R. Junqueira & 15 \\
\hline Artur Roberto do Nascimento & 13 \\
\hline Fernando Dal-Ri Murcia & 12 \\
\hline Octavio R. de Mendonça Neto & 12 \\
\hline Ricardo Lopes Cardoso & 12 \\
\hline Carlos Alberto Diehl & 11 \\
\hline Gilberto de Andrade Martins & 11 \\
\hline José C. Tiomatsu Oyadomari & 11 \\
\hline Maria Thereza Pompa Antunes & 10 \\
\hline Betty Lilian Chan & 9 \\
\hline Fabiana Lopes da Silva & 9 \\
\hline Filipe Bressanelli Azevedo & 9 \\
\hline Flávio Leonel de Carvalho & 9 \\
\hline Gerlando A. S. Franco de Lima & 9 \\
\hline Gustavo Amorim Antunes & 9 \\
\hline Ilse Maria Beuren & 9 \\
\hline Marcos Antonio de Souza & 9 \\
\hline Marke Miranda de Mendonça & 9 \\
\hline Ademir Clemente & 8 \\
\hline Adriano Mussa & 8 \\
\hline Amaury José Rezende & 8 \\
\hline Carlos Alberto Pereira & 8 \\
\hline Claudio Parisi & 8 \\
\hline José Alonso Borba & 8 \\
\hline Luiz Paulo Lopes Fávero & 8 \\
\hline Marcelo A. da Silva Macedo & 8 \\
\hline Ariovaldo dos Santos & 7 \\
\hline Bruno Meirelles Salotti & 7 \\
\hline Ernani Ott & 7 \\
\hline Fábio Frezatti & 7 \\
\hline Hans Michael Van Bellen & 7 \\
\hline Idalberto José das Neves Júnior & 7 \\
\hline Jeronymo José Libonati & 7 \\
\hline Luiz João Corrar & 7 \\
\hline Mauro Fernando Gallo & 7 \\
\hline Paulo Cesar Starke Junior & 7 \\
\hline Viviane da Costa Freitag & 7 \\
\hline
\end{tabular}

Similarmente às constatações dos dois primeiros triênios, apenas 3 dos 26 auto- res destacados na Tabela 9 não integram a Tabela 10; os autores nominados integram ambas as Tabelas. Logo, mais uma vez, os autores mais prolíficos apresentaram o maior número de laços relacionais. Com relação ao trânsito dos autores, verificou-se que pouco mais 5\% dos 1.120 pesquisadores totais estiveram presentes nos três triênios, indicando, assim, que há variabilidade dos atores que têm contribuído para a manutenção do campo de pesquisa científica em Contabilidade (considerando o universo do Congresso explorado).

\subsection{Uma visão geral Congresso USP de Controladoria e Contabilidade}

Observada cumulativamente nos 9 anos, a lista de autores mais prolíficos não apresentou variações muito significativas em relação às constatações trienais exploradas nas seções precedentes. Em linhas gerais, os autores que mais publicaram a cada triênio foram os mesmos que se destacaram na análise do Congresso como um todo. Essa constatação indica que tais pesquisadores desenvolveram seus estudos com relativa periodicidade, ou seja, esforçaram-se continuamente para a produção do conhecimento científico gerado, indicando gradual avanço intelectual na manutenção do campo de conhecimento da Contabilidade. Cumpre salientar que o padrão constatado nos dados das redes apresentadas pode ser reflexo do conhecimento acumulado dos autores sobre os assuntos abordados, característica relevante para a profundidade do saber científico.

Identificou-se apenas uma ocorrência de pesquisador com artigos selecionados em todas as 9 edições do Congresso USP de Controladoria e Contabilidade exploradas: Ilse Beuren. A autora foi, também, a mais prolífica do campo analisado, com 18 artigos selecionados no período 2001-2009. Na sequência, Luiz Corrar, César Silva e Gilberto Martins estiveram presentes como autores ou 
coautores de artigos selecionados em 8 edições do referido evento. A Tabela 11 reúne os
13 pesquisadores com mais de 10 artigos selecionados nas 9 edições estudadas do evento.

Tabela 11 Autores mais prolíficos no período 2001-2009

\begin{tabular}{|c|c|c|c|c|c|c|c|c|c|c|c|c|c|}
\hline \multirow{2}{*}{ AUTORES } & \multicolumn{4}{|c|}{$1^{\circ}$ TRIÊNIO } & \multicolumn{4}{|c|}{$2^{\circ}$ TRIÊNIO } & \multicolumn{4}{|c|}{$3^{\circ}$ TRIÊNIO } & \multirow{2}{*}{$\begin{array}{c}\text { TOTAL } \\
\text { 01-09 }\end{array}$} \\
\hline & 01 & 02 & 03 & $\mathbf{T}$ & 04 & 05 & 06 & $\mathbf{T}$ & 07 & 08 & 09 & $\mathbf{T}$ & \\
\hline Ilse Maria Beuren & 1 & 3 & 2 & 6 & 2 & 2 & 2 & 6 & 2 & 3 & 1 & 6 & 18 \\
\hline Luiz João Corrar & & 1 & 4 & 5 & 6 & 1 & 1 & 8 & 1 & 1 & 2 & 4 & 17 \\
\hline César Augusto Tibúrcio Silva & 1 & 2 & 3 & 6 & 2 & 3 & 3 & 8 & 1 & & 1 & 2 & 16 \\
\hline Gilberto de Andrade Martins & 1 & & 5 & 6 & 2 & 1 & 2 & 5 & 2 & 2 & 1 & 5 & 16 \\
\hline Maísa de Souza Ribeiro & & & 5 & 5 & 5 & & 2 & 7 & 2 & 1 & & 3 & 15 \\
\hline $\begin{array}{l}\text { Aridelmo J. Campanharo } \\
\text { Teixeira }\end{array}$ & & 1 & 4 & 5 & 3 & 2 & 1 & 6 & 1 & 1 & & 2 & 13 \\
\hline Paulo Roberto Barbosa Lustosa & & & 1 & 1 & 4 & 3 & 3 & 10 & 2 & & & 2 & 13 \\
\hline Valmor Slomski & & & 6 & 6 & 2 & 1 & 2 & 5 & 1 & 1 & & 2 & 13 \\
\hline Antonio Lopo Martinez & & & 1 & 1 & 3 & 2 & 2 & 7 & 1 & 1 & 2 & 4 & 12 \\
\hline Fábio Moraes da Costa & 1 & 1 & & 2 & 3 & 2 & 3 & 8 & 1 & 1 & & 2 & 12 \\
\hline Jorge Katsumi Niyama & 1 & 5 & & 6 & & 1 & 2 & 3 & 1 & 1 & 1 & 3 & 12 \\
\hline Marcelle Colares Oliveira & 1 & & 2 & 3 & 3 & 1 & 3 & 7 & 1 & & & 1 & 11 \\
\hline Valcemiro Nossa & & 1 & 2 & 3 & 4 & 1 & 1 & 6 & 1 & 1 & & 2 & 11 \\
\hline TOTAL & 6 & 14 & 35 & 55 & 39 & 20 & 27 & 86 & 17 & 13 & 8 & 38 & 179 \\
\hline
\end{tabular}

A produção científica dos autores constantes da Tabela 11 esteve concentrada no triênio 2004-2006, o que pode sinalizar mudanças no perfil das redes de cooperação estruturadas entre os pesquisadores, especialmente no que diz respeito à presença dos atores mais centrais (prolificidade, centralidades de grau e de intermediação), sugerindo estar havendo entrada de novos atores no campo de pesquisa em Contabilidade, o que é bastante positivo. Os autores mais prolíficos envolveram-se em 162 artigos selecionados nos 9 anos do Congresso, indicando assim, que 13 autores responderam, juntamente com seus parceiros, por $18,37 \%$ da produção científica constante dos anais do evento como um todo.

Ressalte-se que não foi objeto de avaliação da presente investigação identificar características específicas de relacionamento entre os autores, relatando se a produção científica é proveniente de grupos de pesquisa, disciplinas cursadas ou relacionamentos de parceria entre pesquisadores. Contudo, é possível afirmar que algumas parcerias foram recorrentes, o que pode significar a longevidade de redes de pesquisa estabelecidas. A seguir, têm-se as argumentações conclusivas do presente estudo.

\section{CONCLUSÕES}

A partir de conceitos fundamentais de redes sociais de colaboração, delineou-se o perfil das redes de cooperação configuradas entre os pesquisadores com artigos científicos selecionados nas 9 edições do Congressos USP de Controladoria e Contabilidade reali- zadas no período 2001-2009. Foram descritas e analisadas as características e mudanças ocorridas na configuração das redes de colaboração (coautoria) formadas nesse período como alternativa para mapear, a partir da estrutura de relacionamento, a forma de coope- 
ração manifestada entre os atores com artigos aceitos no referido evento.

A análise dos dados do período 2001-2009 evidenciou que os pesquisadores se organizaram de forma fragmentada, ou seja, as redes de cooperação mostraram-se constituídas por diversos componentes em todos os períodos estudados. Em linhas gerais, as principais sub-redes de cada um dos períodos analisados reuniram os pesquisadores relevantes em termos de número de artigos selecionados e centralidades de grau e de intermediação.

$\mathrm{O}$ universo estudado mostrou-se caracterizado pela presença de lacunas estruturais, ou seja, verificou-se que alguns atores não estiveram exclusivamente ligados a contatos redundantes. Como decorrência desse formato de cooperação, alguns atores ocuparam posição privilegiada na estrutura da rede, mostrandose abertos a outros grupos e assumindo a posições de pontes que ligaram pesquisadores que não estariam conectados sem a sua presença. Confirmando que atores intermediadores têm potencial impacto no controle informacional da rede, os pesquisadores configurados como intermediadores foram os mais prolíficos nos períodos analisados, reforçando, assim, a importância do contato com grupos distintos de colaboração, especialmente quando se fala de um campo relativamente "jovem" se comparado a outras ciências sociais, como é o caso da Contabilidade.

Nesses termos, os atores intermediadores não ficaram restritos a um grupo fechado de pesquisadores; conectaram-se com atores que, teoricamente, tendem a compartilhar recursos não imbricados em um mesmo círculo de convívio. A partir desse olhar, tem-se uma importante consideração para o incremento da produção científica em Contabilidade.

Apesar das características recém-comentadas, o perfil das redes de cooperação estudadas mostrou-se predominantemente caracterizado pela presença de laços fortes; perfil esse, que deve ser repensado. Os pesquisadores poderiam refletir um pouco mais acerca do seu formato de cooperação, atentando-se à importância dos laços fracos em estruturas relacionais, conforme destacado por Granovetter (1973, 1983), uma vez que representam alavancas para processos de mudança e inovação. Ainda que contribuam para a consolidação/manutenção de uma relação de confiança e afinidade, os laços fortes podem nutrir relações de dependência, fazendo com que haja acomodação, divisão de tarefas e enrijecimento de ações. Relações enrijecidas tendem a manifestar maior resistência à mudança e à inovação, o que pode constranger a evolução de um campo de pesquisa. Observe-se, ainda, que os integrantes de um grupo que se relaciona predominantemente por meio de laços fortes podem não perceber que manifestam postura resistente ao novo, ou ainda, que se privam de contatar com o novo. É possível que esse grupo fortemente conectado entre si esteja satisfeito por apresentar ideias aparentemente semelhantes e complementares, o que, na linguagem de redes sociais, se poderia denominar de informações redundantes.

Assim, a configuração de uma ampla rede de colaboração, caracterizada, inclusive, pela presença de laços fracos, deve ser visualizada como algo que deve ser incentivado, perseguido. Não se defende, obviamente, que se busque um novo formato de configuração relacional pura e simplesmente com o intuito de exibir, no campo da Contabilidade, um formato mais próximo àquele desejável, pelo menos teoricamente. O que se deseja salientar são os benefícios de se firmarem relacionamentos com grupos mais distantes daquele com o qual o contato é mantido habitualmente, que, em termos mais práticos, proporcionam/despertam o desenvolvimento de pesquisas sob um novo olhar, possibilitando contato com áreas que, apesar de complementares, podem, ainda, não terem sido exploradas conjuntamente, entre outras contribuições.

Embora se tenha identificado um 
perfil de redes de cooperação deficiente em alguns quesitos, cumpre salientar que o universo explorado apresentou sinais de desenvolvimento. A rede teve sua densidade aumentada no último período e a redução do número de atores presentes implicou diminuição das relações fortes. Contudo, verificou-se baixa persistência de pesquisadores, ou seja, houve acentuada variabilidade dos atores constituintes do universo analisado. Considerando que a realização de pesquisas científicas e sua posterior publicação constituem-se em um processo desejado por muitos pesquisadores, mas nem sempre alcançado por todos, é possível depreender que o desenvolvimento de pesquisas deve configurar-se como uma prática dinâmica, ou seja, que deve ser continuamente perseguida. Nesse sentido, a permanência de apenas 62 pesquisadores nos três triênios estudados pode sinalizar uma limitação da área de Contabilidade, uma vez que um pequeno número de indivíduos esforça-se constantemente pela manutenção do campo. Reconhece-se, no entanto, que o levantamento relativo ao trânsito de autores está condicionado ao universo pesquisado, não podendo ser considerado como um indicativo de que os demais autores não tenham desenvolvido outras investigações.

Quanto às limitações do presente estudo, saliente-se a parcialidade do mapeamento da perspectiva colaborativa, haja vista que o levantamento realizado restringiu-se às indicações de autoria e coautoria dos artigos selecionados no Congresso USP de Controladoria e Contabilidade [2001-2009]. Ressalte-se, também, que os achados estão limitados pelo evento eleito para a realização da pesquisa, não se podendo realizar extrapolações para a produção científica definitiva (publicada em periódicos).

No que tange às implicações práticas e acadêmicas, salientem-se algumas observações. Academicamente, os resultados do presente estudo fornecem indícios da importância que a formação de redes de coopera- ção assume no ambiente acadêmico, uma vez que podem ser consideradas como forma de acesso a uma variedade de recursos e, ain$\mathrm{da}$, como fonte de apoio para o incremento do potencial da produção científica contábil. Em termos mais práticos, os resultados deste estudo representam um instrumento de diagnóstico situacional do perfil das redes de cooperação configuradas no Congresso USP de Controladoria e Contabilidade. Complementarmente, diante de um grande número de pesquisadores que têm metas comuns e vislumbra a internacionalização como necessidade premente, o estudo instiga reflexões sobre a coordenação de esforços que se poderia instaurar no sentido de promover a colaboração científica, em seu sentido amplo, como forma de cooperar para a manutenção e evolução de um empreendimento tão relevante na comunidade acadêmica: a pesquisa em Contabilidade.

Como agenda de pesquisas futuras, sugere-se a realização de um levantamento com finalidade de indicar a parcela de artigos que, depois de selecionada no Congresso USP de Controladoria e Contabilidade, foi veiculada em periódicos científicos. Esses achados poderiam proporcionar revelações adicionais ao presente estudo, averiguando, assim, a continuidade do processo inicialmente articulado a partir da veiculação de pesquisas em congresso científico. De forma complementar, recomenda-se, também, a exploração da estrutura de relações e das parcerias que, porventura, tenham originado tais publicações (os parceiros permaneceram os mesmos? houve ingresso de novos autores? qual o perfil de relacionamento dessas parcerias, se proveniente da relação professor-aluno, grupos de pesquisa, parcerias de pesquisa, entre outras?).

Adicionalmente, recomenda-se a realização de estudos mediante a obtenção de informações diretamente com os pesquisadores, buscando compreender os fatores que deram origem ao processo de constituição das redes 
de cooperação formadas. Aconselha-se, também, que sejam explorados aspectos ligados às temáticas e às perspectivas teóricas e metodológicas das pesquisas. Nesse sentido, salientese que Moddy (2004) constatou que pesquisas quantitativas têm mais coautores do que pes- quisas não quantitativas. Por fim, sugere-se que sejam realizadas investigações periódicas a respeito do evento em questão, de forma a contribuir para um "olhar para si mesmo", uma vez que a autorreflexão se constitui em elemento de desenvolvimento da ciência.

\section{Referências}

ACEDO, F. J.; BARROSO, C.; CASANUEVA, C.; GALÁN, J. L. Co-Authorship in Management and Organizational Studies: an Empirical and Network Analysis. Journal of Management Studies, v. 43, n. 5, p. 957-983. Jul./2006.

BARABÁSI, A. L.; JEONG, H.; NÉDA, Z.; RAVASZ, E.; SCHUBERT, A.; VICSEK, T. Evolution of the Social Network of Scientific Collaborations. Physic A, v. 311. p. 590-614, 2002.

BITTENCOURT, O. N. da S.; KLIEMANN NETO, F. J. Rede Social no Sistema de Saúde: Um Estudo das Relações Interorganizacionais em Unidade de Serviços de HIV/AIDS. Revista de Administração Contemporânea; v. 13, edição especial, p. 87-104, 2009.

BORGATTI, S.P.; EVERETT, M.G.; FREEMAN, L.C. Ucinet for Windows: Software for Social Network Analysis. Harvard, MA: Analytic Technologies. 2002. BURT, R. S. Structural Holes and Good Ideas. American Journal of Sociology, v. 110, n. 2, p. 349-399, Sep./2004. CAPES - COORDENAÇÃO DE APERFEIÇOAMENTO DE PESSOAL DE NÍVEL SUPERIOR. Disponível em: <http://www.capes.gov.br>. Acesso em: 02 fev. 2010. CARDOSO, R. L.; MENDONÇA NETO, O. R.; RICCIO, E. L.; SAKATA, M. C. G. Pesquisa Científica em Contabilidade entre 1990 e 2003. Revista de Administração de Empresas, v. 45, n. 2, p. 34-45, abr./jun. 2005.

CONCEIÇÃO, M. I. G. Os colaboradores em um artigo científico. Psicologia: Teoria e Pesquisa, v. 24, n. 2, p.1-3, Abr./Jun. 2008.

DEGENNE, A.; FORSÉ, M. Introducing Social Networks. London: Sage Publications, 1999.

ENGLEBRECHT, T. D.; HANKE, S. A.; KUANG, Y. An Assessment of Patterns of Co-authorship for Academic Accountants within Premier Journals: Evidence from 1979-2004. Advances in Accounting, Incorporating Advances in International Accounting, v. 25, n. 2, p. 172181, 2008.

EMIRBAYER, M.; GOODWIN, J. Network Analysis, Culture and the Problem of Agency. American Journal of Sociology, v. 99, n. 6, p. 1411-1454, 1994.

FLEISCHAMN, R. K.; SCHUELE, K. Co-authorship in Accounting History: Advantages and Pitfalls. Accounting History Review, v. 19, p. 287 - 303, 2009.

GRAEML, A. R.; MACADAR, M. A.; GUARIDO

FILHO, E.; ROSSONI, L. Redes Sociais e Intelectuais em Administração da Informação: Uma Análise Cientométrica do Período 1997-2006. Informação \& Sociedade, v. 20, p. 95-110, 2010.
GRANOVETTER, M. S. The Strength of Weak Ties. The American Journal of Sociology, v. 78, n. 6, p. 1360-1280, May/1973.

. The Strength of Weak Ties: A Network Theory

Revisited. Sociological Theory, v. 1, p. 201-233, 1983. GUARIDO FILHO, E. R. A Construção da Teoria Institucional nos Estudos Organizacionais no Brasil: o Período 1993-2007. 299f. Tese (Doutorado em Administração), Universidade Federal do Paraná. Curitiba, 2008.

HANNEMAN, R. A.; Riddle, M. Introduction to Social Network Methods. Riverside: University of California, 2005. KATZ, J. S.; MARTIN, B. R. What is Research Collaboration? Research Policy, n.26, p.1-18, 1997. LIU, X.; BOLLEN, J.; NELSON, M. L.; SOMPEL, H. V. Co-authorship Networks in the Digital Library Research Community. Information Processing and Management. v. 41, p. 1462-1480, 2005.

MACHADO-DA-SILVA, C. L.; COSER, C. Isomorfismo Mimético e Lacunas Estruturais em um Campo Organizacional. In: CRUZ, J. A. W.; MARTINS, T. S.; AUGUSTO, P. O. M. Redes Sociais e Organizacionais em Administração. Curitiba: Juruá, 2008. p. 69-90. MARTINS, G. A. Manual para Elaboração de Monografias e Dissertações. 3.ed. São Paulo: Atlas, 2002. MARTINS, G. S. A Construção do Conhecimento Científico no Campo de Gestão de Operações no Brasil: uma Análise sob a ótica de Redes Sociais do Período 1997 2008. 184f. Dissertação (Mestrado em Administração) - Escola de Administração de Empresas de São Paulo, São Paulo, 2009.

MELLO, C. M.; CRUBELLATE, J. M.; ROSSONI, L. Dinâmica de Relacionamento e Prováveis Respostas Estratégicas de Programas Brasileiros de Pós-Graduação em Administração à Avaliação da CAPES: Proposições Institucionais a partir da Análise de Redes de CoAutorias. Revista de Administração Contemporânea, v. 14, n. 3, p. 434-457, maio/jun. 2010.

MEMON, N.; LARSEN, H. L.; HICKS, D. L.;

HARKIOLAKIS, N. Detecting Hidden Hierarchy in Terrorist Networks: Some Case Studies. In: YANG, C. C.; CHEN, H.; CHAU, M.; CHANG, K; LANG, S.; CHEN, P. S; HSIEH, R. ZENG, D.; WANG, F.; CARLEY, K.; MAO, W.; ZHAN, J. (Eds.) Intelligence and Security Informatics. Lecture Notes in Computer Science, v. 5975. p. 477-489, 2008. MOODY, James. The Structure of a Social Science Collaboration Network: Disciplinary Cohesion from 1963 to 1999. American Sociological Review, v. 69, n. 2, p. 213-238, Apr./2004. 
NASCIMENTO, A. R. do; JUNQUEIRA, E.; MARTINS, G. de A. Pesquisa Acadêmica em Contabilidade Gerencial no Brasil: Análise e Reflexões sobre Teorias, Metodologias e Paradigmas. Revista de Administração Contemporânea, v. 14, n. 6, p. 1113-1133, nov./dez. 2010. NASCIMENTO, S. do; BEUREN, I. M. Redes Sociais na Produção Científica dos Programas de Pós-Graduação de Ciências Contábeis do Brasil. Revista de Administração Contemporânea, v. 15, n. 1, p. 47-66, jan./fev. 2011. OTTE, E.; ROUSSEAU, R. Social Network Analysis: a Powerful Strategy, also for the Information Sciences. Journal of Information Science, v. 28, n. 6, p. 441-453, 2002. OWEN-SMITH, J.; POWELL, W. W. Networks and Institutions. In: GREENWOOD, R.; OLIVER, C.; SAHLIN, K.; SUDDABY, R. The Sage Handbook of Organizational Institutionalism. London: Sage Publications. p. 596-623, 2008.

ROSSONI, L. A Dinâmica de Relações no Campo da Pesquisa em Organizações e Estratégia no Brasil: Uma Análise Institucional. 296 f. Dissertação (Mestrado em Administração) - Universidade Federal do Paraná, Curitiba, 2006.
RUTLEDGE, R.; KARIM, K. Determinants of Coauthorship for the Most Productive Authors of Accounting Literature. Journal of Education for Business, p. 130-134. Jan./Feb. 2009.

SCOTT, J. Social Network Analysis: a Handbook. 2. ed. London: Sage Publications, 2000.

SILVA, A. B. de O.; MATHEUS, R. F.; PARREIRAS, F, S,. PARREIRAS, T. A. S. Análise de Redes Sociais como Metodologia de Apoio para a Discussão da Interdisciplinaridade na Ciência da Informação. Ciência da Informação, v. 35, n. 1, p. 72-93, jan./abr. 2006. ULYSAL, Ö. Ö. Business Ethics Research with an Accounting Focus: A Bibliometric Analysis from 1988 to 2007. Journal of Business Ethics, v. 93, n. 1, p. 137-160, 2010.

WAKEFIELD, R. Networks of Accounting Research: a Citation-based Structural and Network Analysis. The British Accounting Review, v. 40, p. 228-244, 2008. WASSERMAN, S.; FAUST, K. Social Network Analysis: Methods and Applications. Cambridge: Cambridge University Press, 1994. 